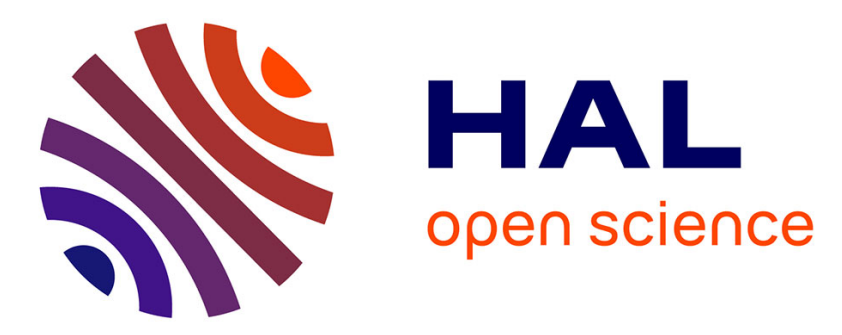

\title{
Possible role of azole and echinocandin lock solutions in the control of biofilms associated with silicone
}

\author{
Estelle Cateau, Jean-Marc Berjeaud, Christine Imbert
}

\section{To cite this version:}

Estelle Cateau, Jean-Marc Berjeaud, Christine Imbert. Possible role of azole and echinocandin lock solutions in the control of biofilms associated with silicone. International Journal of Antimicrobial Agents, 2011, 37 (4), pp.380. 10.1016/j.ijantimicag.2010.12.016 . hal-00679595

\section{HAL Id: hal-00679595 \\ https://hal.science/hal-00679595}

Submitted on 16 Mar 2012

HAL is a multi-disciplinary open access archive for the deposit and dissemination of scientific research documents, whether they are published or not. The documents may come from teaching and research institutions in France or abroad, or from public or private research centers.
L'archive ouverte pluridisciplinaire HAL, est destinée au dépôt et à la diffusion de documents scientifiques de niveau recherche, publiés ou non, émanant des établissements d'enseignement et de recherche français ou étrangers, des laboratoires publics ou privés. 


\section{Accepted Manuscript}

Title: Possible role of azole and echinocandin lock solutions in the control of Candida biofilms associated with silicone

Authors: Estelle Cateau, Jean-Marc Berjeaud, Christine Imbert

PII: S0924-8579(11)00037-9

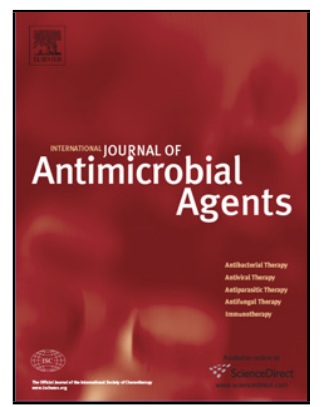

DOI: doi:10.1016/j.ijantimicag.2010.12.016

Reference: ANTAGE 3529

To appear in:

International Journal of Antimicrobial

Agents

Received date: 2-9-2010

Revised date: 20-12-2010

Accepted date:

Please cite this article as: Cateau E, Berjeaud J-M, Imbert C, Possible role of azole and echinocandin lock solutions in the control of Candida biofilms associated with silicone, International Journal of Antimicrobial Agents (2010), doi:10.1016/j.ijantimicag.2010.12.016

This is a PDF file of an unedited manuscript that has been accepted for publication. As a service to our customers we are providing this early version of the manuscript. The manuscript will undergo copyediting, typesetting, and review of the resulting proof before it is published in its final form. Please note that during the production process errors may be discovered which could affect the content, and all legal disclaimers that apply to the journal pertain. 


\section{Possible role of azole and echinocandin lock solutions in the control of Candida biofilms associated with silicone}

Estelle Cateau *, Jean-Marc Berjeaud, Christine Imbert

UMR CNRS 6008, Université de Poitiers, 6 rue de la Milètrie, BP 199, 86034 Poitiers Cedex, France

\section{ARTICLE INFO}

Article history:

Received 2 September 2010

Accepted 21 December 2010

Keywords:

Candida

Biofilm

Lock solution

Echinocandin

Posaconazole

* Corresponding author. Tel.: +33 5494437 47; fax: +33 549443908.

E-mail address: christine.imbert@univ-poitiers.fr (E. Cateau). 


\section{ABSTRACT}

Until now, management of candidiasis related to implanted devices has remained problematic. The aim of this study was to investigate antifungal lock strategies against Candida albicans and Candida glabrata biofilms in vitro. Three antifungal agents were used against eight $C$. albicans and six $C$. glabrata clinical strains isolated from infected catheters. Caspofungin and micafungin, both echinocandins, as well as the azole posaconazole were tested. An in vitro model of Candida biofilm on $100 \%$ silicone catheters was used. Efficacy of the antifungal lock was tested against biofilms aged $12 \mathrm{~h}$ and 5 days following exposure to caspofungin $(5 \mathrm{mg} / \mathrm{L}$ and $25 \mathrm{mg} / \mathrm{L})$, micafungin (5 mg/L and $15 \mathrm{mg} / \mathrm{L})$ and posaconazole $(10 \mathrm{mg} / \mathrm{L})$ for $12 \mathrm{~h}$. Persistence of antibiofilm activity was investigated 1-3 days following drug elimination. Antifungal lock was considered effective in the event of a significant decrease $(P<0.001)$ in the metabolic activity of the biofilm yeast. The results showed that micafungin had significant inhibitory effectiveness against young and mature $C$. albicans and C. glabrata biofilms. Moreover, this activity appeared to persist for up to 3 days. Caspofungin displayed similar activity against all $C$. albicans biofilms, but the activity was less persistent for $C$. glabrata biofilms. Posaconazole was less effective against C. albicans biofilms, but its activity was sustained. Echinocandin lock therapy could significantly enhance the management of candidiasis in patients with indwelling catheters by combating biofilms and enabling device maintenance in situ. 


\section{Introduction}

Candida spp. are one of the most common causes of hospital-acquired infections. Candidaemia is frequently associated with intravascular catheter-related infections, which is usually correlated with the formation of a biofilm. The biofilm alters the yeast's susceptibility to antifungal agents $[1,2]$.

The French Society for Hospital Hygiene recommends that peripheral venous catheters be maintained for no more than $96 \mathrm{~h}$ (http://www.sfhh.net). Central venous catheters are to be left in situ until colonised. When candidiasis has been documented, it is currently recommended that the central venous catheter should be removed [3]. However, in many patients with catheter-related Candida infection, removal of an infected device requires its replacement by a new one. In addition, this procedure generates additional costs. The antibiotic lock technique may constitute an alternative with regard to the prevention and treatment of intravascular catheterrelated infections, particularly insofar as the technique would enable catheter maintenance in situ. The lock technique involves instillation of high concentrations of an antimicrobial agent directly into the catheter in order to 'lock' it for several hours or days. The antimicrobial solution fills the lumen without spilling into the circulation [4]. In 2005, Lepape [5] showed that the antibiotic concentrations used for lock therapy and effective on biofilm microorganisms were approximately 100-1000-fold the minimum inhibitory concentration (MIC).

The role of antifungal lock solutions is not well defined [3] as few reports on their use in clinical practice are available in the literature $[6,7]$. 
The activity of echinocandins on biofilms has already been demonstrated in vitro $[2,8]$. These agents are known to have potent and lasting antifungal and antibiofilm activity [9]. Used as lock solutions, echinocandins could be particularly useful against catheter infections.

The in vitro efficacy of echinocandin lock solutions with respect to Candida albicans biofilm growth was investigated in a preliminary study (two strains). The results suggested that micafungin and caspofungin indeed reduced the metabolic activity of C. albicans growing as biofilm. Moreover, this reduction was maintained for up to 72 $\mathrm{h}$ post lock, suggesting a persistent effect [10].

A few recent articles suggest that posaconazole treatment ( $\geq 24 \mathrm{~h}$ ) does not reduce the metabolic activity of $C$. albicans in biofilms by $>50 \%[9,11]$. Posaconazole was included in the current study to investigate its antibiofilm activity as a short-term treatment (12 h).

The aim of this study was to confirm the preliminary results obtained with micafungin and caspofungin lock solutions against $C$. albicans biofilms using eight additional strains isolated from infected catheters (Table 1). The study was then extended to include Candida glabrata species, including six strains isolated from infected catheters (Table 1). Subsequently, the antibiofilm activity of posaconazole lock solution was investigated using the same strains of $C$. albicans and $C$. glabrata. 


\section{Materials and methods}

All the strains studied are referenced in Table 1. MIC values were determined using Etest strips in accordance to the manufacturer's instructions (AB BIODISK, Solna, Sweden).

Strains were identified using conventional methods such as the germ tube test in serum, agglutination (Bichrolatex; Fumouze, Levallois-Perret, France) and metabolic properties (API20C; bioMérieux, Marcy-l'Étoile, France).

Yeasts were first cultured on Sabouraud agar slants (Sanofi Diagnostics Pasteur, Marnes-La-Coquette, France) at $37^{\circ} \mathrm{C}$ for $48 \mathrm{~h}$. A loopful of the culture was then transferred to $25 \mathrm{~mL}$ of Yeast Nitrogen Base medium (Difco, Detroit, Ml) supplemented with $30 \mathrm{mM}$ of glucose (Sigma, St Louis, MO) (YNB-Glc) and was incubated without shaking at $37^{\circ} \mathrm{C}$ for $16 \mathrm{~h}$.

Blastospores were then harvested, washed twice in $0.1 \mathrm{M}$ phosphate-buffered saline (PBS) (pH 7.2) (bioMérieux) and adjusted to a concentration of $5 \times 10^{6}$ blastospores/mL in YNB-Glc for use in the biofilm experiments.

Candida biofilms aged $12 \mathrm{~h}$ (young biofilm) and 5 days (mature biofilm) were formed in untreated microtitre plates (Corning Inc., Corning, NY) as previously described using $5 \mathrm{~mm}$ sections of $100 \%$ silicone catheters (A-M Systems, Carlsberg, WA) [10]. These maturation stages were chosen arbitrarily. For the 5-day incubation period, media were replenished every 2 days with up to $300 \mu \mathrm{L}$ of YNB-Glc to compensate 
for evaporation. Prior to biofilm production, catheter sections were autoclaved, incubated overnight in neat fetal bovine serum and washed with YNB-Glc.

Stock solutions were prepared as follows: $2 \mathrm{mg} / \mathrm{mL}$ caspofungin (Merck Research Laboratories, Rahway, NJ) stock solution in sterile distilled water; $2 \mathrm{mg} / \mathrm{mL}$ micafungin (Astellas Pharma Inc., Tokyo, Japan) stock solution in sterile distilled water; and $1 \mathrm{mg} / \mathrm{mL}$ posaconazole (Schering-Plough, Kenilworth, $\mathrm{NJ}$ ) stock solution in dimethyl sulphoxide (DMSO). Antifungal stock solutions were then diluted in YNBGlc. Caspofungin, micafungin and posaconazole concentrations tested were approximately $100-500 \times$ MIC and were thus compatible with the lock therapy strategy [4]. Subsequently, $300 \mu \mathrm{L}$ of $5 \mathrm{mg} / \mathrm{L}$ or $25 \mathrm{mg} / \mathrm{L}$ caspofungin, $5 \mathrm{mg} / \mathrm{L}$ or 15 $\mathrm{mg} / \mathrm{L}$ micafungin, or $10 \mathrm{mg} / \mathrm{L}$ posaconazole solution were added to pre-formed biofilms and the plates were incubated at $37^{\circ} \mathrm{C}$ for $12 \mathrm{~h}$. Controls consisted of biofilms incubated with $300 \mu \mathrm{L}$ of YNB-Glc for $12 \mathrm{~h}$. All the silicone sections were then moved to new wells and were incubated with YNB-Glc without an antifungal agent at $37^{\circ} \mathrm{C}$ for 24,48 or $72 \mathrm{~h}$ for young biofilms and for $24 \mathrm{~h}$ or $48 \mathrm{~h}$ for mature biofilms in order to evaluate the persistence of antibiofilm activity.

Antibiofilm effects were monitored using a previously described metabolic assay based on the reduction of a tetrazolium salt (XTT) [12]. Briefly, each catheter section coated with biofilm and either exposed or not exposed to antifungal solution was incubated with XTT (300 mg/L) and menadione $(0.13 \mathrm{mM})$ in $150 \mu \mathrm{L}$ of PBS at $37^{\circ} \mathrm{C}$ for $3 \mathrm{~h}$. Absorbance was then measured at $492 \mathrm{~nm}\left(\mathrm{~A}_{492}\right)$ in a microplate reader (LP400; Sanofi Diagnostics Pasteur). Absorbance indicates the metabolic activity of the yeast in the biofilm. All experiments were performed twice with eight replicates. 
Analysis of variance (ANOVA) and Scheffe's test were performed to determine whether the between-group differences were statistically significant.

To facilitate analysis of the results, the activity inhibition percentages were calculated as follows: inhibition $(\%)=100 \times\left[1-\left(A_{492}\right.\right.$ lock-treated strain/ $A_{492}$ untreated strain $\left.)\right]$.

\section{Results and discussion}

Young biofilms were used as an in vitro model of peripheral or central venous catheters, which may be colonised within a few hours of insertion. Persistence of lock activity was studied up to $72 \mathrm{~h}$ post treatment because catheters may be left in situ for up to $96 \mathrm{~h}$.

The results obtained against $C$. albicans young biofilms $24 \mathrm{~h}$ post echinocandin lock are shown in Table 2. For all the strains, the mean decrease in metabolic activity of the biofilm yeasts due to the antifungal lock was expressed as a function of the antifungal drug and test concentration.

Inhibition of biofilm yeast growth ranged from $46 \%$ (5 mg/L caspofungin, strain 1119) to $89 \%$ (5 mg/L caspofungin, strain 1137 ), depending on the strain, antifungal agent and test concentration.

Persistence of activity was evaluated $48 \mathrm{~h}$ and $72 \mathrm{~h}$ after removal of the antifungal solutions. The inhibitory activities of caspofungin and micafungin lock solutions against young $C$. albicans biofilms were sustained $48 \mathrm{~h}$ and $72 \mathrm{~h}$ post lock, 
irrespective of the strain concerned. Inhibition ranged from $32 \%$ (5 mg/L micafungin, strain 1119$)$ to $92 \%$ (15 mg/L micafungin, strain 1160$)$ at $48 \mathrm{~h}$ post lock. The young biofilms of strains 1126 and 1163 exhibited $>80 \%$ inhibition up to 3 days post lock.

Despite some differences between C. albicans strains, inhibition of metabolic activity persisted for up to $72 \mathrm{~h}$ post lock. There was no significant difference between the activities of caspofungin and micafungin.

Results suggested that, irrespective of the antifungal concentration and test strain concerned, caspofungin and micafungin locks exerted a significant $(P<0.001)$ inhibitory activity (>70\%) against young C. albicans biofilms.

Interestingly, the highest echinocandin concentrations $(500 \times \mathrm{MIC})$ did not have a significantly greater antibiofilm activity than the lowest concentrations (100-200x MIC). A paradoxical effect could explain this phenomenon [13]. However, the highest concentration tested in the current study corresponds to one of the lowest concentrations involved in the paradoxical effect, so it was not possible to establish this explanation. These results need to be confirmed in clinical practice but suggest that it may not be necessary to use the highest concentrations. This would also be a more cost-effective approach.

The activities of caspofungin and micafungin lock solutions were then tested against mature C. albicans biofilm. Persistence of activity was monitored over a 48-h period post lock (Table 3). In clinical practice, mature biofilms only occur with central venous catheters, since peripheral venous catheters are changed every $96 \mathrm{~h}$. 
With all the strains under study, $24 \mathrm{~h}$ after the echinocandin lock, inhibition of mature C. albicans biofilms ranged from $44 \%$ (5 mg/L micafungin, strain 1119$)$ to $90 \%$ (25 $\mathrm{mg} / \mathrm{L}$ caspofungin, strain 1160).

Both echinocandins exerted a significant inhibitory activity $(P<0.001)$ on mature biofilms for $48 \mathrm{~h}$ post lock. This inhibition ranged from $28 \%$ ( $25 \mathrm{mg} / \mathrm{L}$ caspofungin, strain 1119$)$ to $92 \%$ (25 mg/L caspofungin, strain 1163).

The weakest inhibitory activity was observed with young and mature biofilms of $C$. albicans strain 1119, even though the MIC of caspofungin was $0.064 \mathrm{mg} / \mathrm{L}$, indicating strain susceptibility (Table 1).

These results showed that, irrespective of biofilm age, both caspofungin and micafungin locks induced an inhibition of $C$. albicans biofilm growth. This suggests that lock approaches may be useful when used in combination with systemic antifungal therapy to eradicate $C$. albicans biofilms on catheters, as has already been demonstrated in vivo by Shuford et al. [14]. However, these authors' studies were based on 8-h or 7-day locks using amphotericin B or caspofungin. They reported that lock therapy was of particular value in the treatment of intraluminal biofilms but had to be combined with treatment of the extraluminal biofilm.

Lock activity of echinocandins was also tested against $C$. glabrata biofilms. However, since the highest concentrations had not been shown to be more effective against $C$. 
albicans biofilms, the study was only performed at an echinocandin concentration of $5 \mathrm{mg} / \mathrm{L}$.

The results for young biofilms at $24 \mathrm{~h}$ post caspofungin or micafungin lock are shown in Table 2. For all the strains, the metabolic activity of biofilm yeasts was significantly reduced post lock ( $\geq 62 \%$ ). For strains 1,767 and 788 , inhibition was significantly greater $(P<0.001)$ following micafungin lock than following caspofungin lock. Mean inhibition reached $92 \%$ with micafungin versus $77 \%$ with caspofungin.

Moreover, the levels of inhibition induced by micafungin lock (ca. 93\%) were similar for all of the strains. Statistical analysis showed that the inhibition induced by caspofungin lock were also similar with all of the strains (range 62-89\%; differences not significant).

Inhibitory activity was shown to persist for $48 \mathrm{~h}$ and $72 \mathrm{~h}$ post lock. Micafungin induced a stronger inhibition $(P<0.01)$ of the metabolic activity of $C$. glabrata biofilms than caspofungin: at $72 \mathrm{~h}$ post lock, micafungin induced a mean level of inhibition $>90 \%$ versus $38 \%$ with caspofungin.

The antibiofilm activity of micafungin on young C. glabrata biofilms persisted for 3 days, whilst that of caspofungin did not.

The results obtained using echinocandin lock on mature $C$. glabrata biofilms at $24 \mathrm{~h}$ and $48 \mathrm{~h}$ post lock showed that, irrespective of echinocandin, the metabolic activity of the yeasts included in mature $C$. glabrata biofilms was significantly reduced $(P<$ 
0.001 ) (caspofungin, 58-87\% inhibition; micafungin, 90-95\% inhibition) at $24 \mathrm{~h}$ post lock. The inhibition induced by micafungin persisted for $48 \mathrm{~h}$ after drug removal (mean inhibition 90\%) and was stronger than that achieved with caspofungin (mean inhibition 44\%) $(P<0.01)$.

Thus, the efficacy of caspofungin locks both on young and mature C. glabrata biofilms was of shorter duration than that of micafungin. To our knowledge, this is the first report of a difference between the activities of caspofungin and micafungin in this context. No obvious hypothesis can explain this difference.

In conclusion, this study thus showed that the antibiofilm potential of caspofungin and micafungin locks with respect both to young and mature $C$. albicans biofilms was maintained for C. glabrata biofilms, although micafungin showed greater sustained efficacy than caspofungin both against young and mature C. glabrata biofilms. These findings are of interest because of the lack of susceptibility of $C$. glabrata to current azoles [1]. In 2006, Seidler et al. [8] reported that 48-h micafungin treatments (0.5-16 $\mathrm{mg} / \mathrm{L})$ were active against $C$. albicans and $C$. glabrata biofilms on polystyrene and silicone elastomers in vitro. The present study has shown that $5 \mathrm{mg} / \mathrm{L}$ micafungin was effective against biofilms of the same species on $100 \%$ silicone even after a shorter exposure time (12 h) than that usually used in lock strategies.

Under the same experimental conditions, the activity of $10 \mathrm{mg} / \mathrm{L}$ posaconazole solutions was tested on $C$. albicans biofilms. The antifungal concentration range was again 100-200× MIC (Table 1). 
Despite some differences between strains, young and mature biofilm growth inhibition reached ca. $50 \%$ at $24 \mathrm{~h}$ post lock (Tables 2 and 3 ). The results concur with those reported by Tobudic et al. [11] and Katragkou et al. [9] Irrespective of whether the biofilm was young or mature, antibiofilm activity remained significant $(P<0.001)$ at $48 \mathrm{~h}$ and $72 \mathrm{~h}$ post lock (41-49\%) (Tables 2 and 3), suggesting a persistence of antibiofilm activity.

Curiously, the inhibition observed for strain 66396 was still ca. 80\% (data not shown). This strain did not have higher posaconazole susceptibility $(\mathrm{MIC}=0.023 \mathrm{mg} / \mathrm{L})$ than the other strains of $C$. albicans in planktonic culture (Table 1), but as a biofilm appeared to be more susceptible to the drug.

Candida albicans biofilms are known to be resistant to azoles [1]. The present results were therefore unexpected. However, the inhibition of metabolic activity was significantly weaker than that observed following echinocandin locks.

Investigation of the efficacy of posaconazole solution against $C$. glabrata biofilms generated similar results (Tables 2 and 3 ) both for young and mature biofilms. Posaconazole was devoid of inhibitory activity on C. glabrata biofilms irrespective of the incubation time post drug elimination. However, the strains of $C$. glabrata under study were all considered resistant to posaconazole, as indicated by their MIC values (Table 1). The results confirmed that the strains remained resistant to posaconazole when cultured as biofilms and overall were consistent with published data. Pfaller et al. [15] had previously demonstrated that planktonic C. glabrata are resistant to fluconazole $\left[\mathrm{MIC}\right.$ for $90 \%$ of the organisms $\left.\left(\mathrm{MIC}_{90}\right)=32 \mathrm{mg} / \mathrm{L}\right]$ and display weak 
susceptibility to posaconazole $\left(\mathrm{MIC}_{90}=2 \mathrm{mg} / \mathrm{L}\right)$. Furthermore, Candida strains embedded in biofilms are known to be less susceptible to azole antifungal agents $[1,12]$

\section{Conclusion}

These findings confirm the potential value of lock strategies in the prevention of silicone-related C. albicans biofilms. Although it was not possible to achieve $100 \%$ biofilm inhibition under the current experimental conditions, use of caspofungin or micafungin could be of value in lock solution management of $C$. albicans infections in combination with systemic antifungal therapy. Similarly, micafungin lock solutions displayed efficacy against $C$. glabrata biofilms. However, caution is required with regard to caspofungin locks. Because their activity is less persistent, it may be necessary to repeat locks more frequently or to use higher antifungal concentrations to ensure effective prevention. Interestingly, posaconazole locks may be partially effective on $C$. albicans biofilms so long as they are used in combination with systemic antifungal therapy.

In conclusion, if used in combination with systemic medication, echinocandin lock therapy may contribute to controlling candidiasis in catheterised patients.

\section{Acknowledgments}

The authors wish to thank Merck, Astellas and Schering-Plough for supporting this study by providing standard antifungal powders of caspofungin, micafungin and posaconazole, respectively. The authors are grateful to O. Eloy (Versailles Hospital, 
France) for supplying a clinical strain of $C$. glabrata as well as to Vicky Hawken, Andrew Mullarky and Jeffrey Arsham for revising the English text.

\section{Funding}

None.

\section{Competing interests}

None declared.

\section{Ethical approval}

Not required. 


\section{References}

[1] Hawser SP, Douglas LJ. Resistance of Candida albicans biofilms to antifungal agents in vitro. Antimicrob Agents Chemother 1995;39:2128-31.

[2] Kuhn DM, George T, Chandra J, Mukherjee PK, Ghannoum MA. Antifungal susceptibility of Candida biofilms: unique efficacy of amphotericin B lipid formulations and echinocandins. Antimicrob Agents Chemother 2002;46:1773-80.

[3] Pappas PG, Kauffman CA, Andes D, Benjamin DK Jr, Calandra TF, Edwards JE Jr, et al. Clinical practice guidelines for the management of candidiasis: 2009 update by the Infectious Diseases Society of America. Clin Infect Dis 2009;48:503-35.

[4] Carratala J. The antibiotic-lock technique for therapy of 'highly needed' infected catheters. Clin Microbiol Infect 2002;8:282-9.

[5] Lepape A. Is there any microbiologically-based specificity of the management of catheter related infections? [in French]. Ann Fr Anesth Reanim 2005;24:298-301.

[6] Angel-Moreno A, Boronat M, Bolanos M, Carrillo A, Gonzalez S, Perez Arellano JL. Candida glabrata fungemia cured by antibiotic-lock therapy: case report and short review. J Infect 2005;51:e85-7.

[7] Viale P, Petrosillo N, Signorini L, Puoti M, Carosi G. Should lock therapy always be avoided for central venous catheter-associated fungal bloodstream infections? Clin Infect Dis 2001;33:1947-8; author reply 9-51.

[8] Seidler M, Salvenmoser S, Muller FM. In vitro effects of micafungin against Candida biofilms on polystyrene and central venous catheter sections. Int $\mathrm{J}$ Antimicrob Agents 2006;28:568-73.

[9] Katragkou A, Chatzimoschou A, Simitsopoulou M, Dalakiouridou M, Diza-Mataftsi $\mathrm{E}$, Tsantali C, et al. Differential activities of newer antifungal agents against 
Candida albicans and Candida parapsilosis biofilms. Antimicrob Agents Chemother 2008;52:357-60.

[10] Cateau E, Rodier MH, Imbert C. In vitro efficacies of caspofungin or micafungin catheter lock solutions on Candida albicans biofilm growth. J Antimicrob Chemother 2008;62:153-5.

[11] Tobudic S, Lassnigg A, Kratzer C, Graninger W, Presterl E. Antifungal activity of amphotericin B, caspofungin and posaconazole on Candida albicans biofilms in intermediate and mature development phases. Mycoses 2010;53:208-14.

[12] Hawser SP, Islam K. Binding of Candida albicans to immobilized amino acids and bovine serum albumin. Infect Immun 1998;66:140-4.

[13] Melo AS, Colombo AL, Arthington-Skaggs BA. Paradoxical growth effect of caspofungin observed on biofilms and planktonic cells of five different Candida species. Antimicrob Agents Chemother 2007;51:3081-8.

[14] Shuford JA, Rouse MS, Piper KE, Steckelberg JM, Patel R. Evaluation of caspofungin and amphotericin B deoxycholate against Candida albicans biofilms in an experimental intravascular catheter infection model. J Infect Dis 2006;194:710-3.

[15] Pfaller MA, Messer SA, Boyken L, Hollis RJ, Rice C, Tendolkar S, et al. In vitro activities of voriconazole, posaconazole, and fluconazole against 4,169 clinical isolates of Candida spp. and Cryptococcus neoformans collected during 2001 and 2002 in the ARTEMIS global antifungal surveillance program. Diagn Microbiol Infect Dis 2004;48:201-5. 


\section{Table 1}

Susceptibility of Candida isolates from infected catheters to caspofungin, micafungin and posaconazole

\begin{tabular}{llllll}
\hline Strain & Species & Source & \multicolumn{2}{l}{ MIC (mg/L) } \\
\cline { 3 - 5 } & & & Caspofungin & Micafungin & Posaconazole \\
\hline 3153 & C. albicans & ATCC & 0.19 & 0.012 & 0.032 \\
66396 & C. albicans & ATCC & 0.064 & 0.004 & 0.023 \\
1119 & C. albicans & Poitiers Hospital & 0.064 & 0.006 & 0.047 \\
1126 & C. albicans & Poitiers Hospital & 0.064 & 0.006 & 0.023 \\
1137 & C. albicans & Poitiers Hospital & 0.094 & 0.016 & 0.064 \\
1150 & C. albicans & Poitiers Hospital & 0.047 & 0.012 & 0.064 \\
1151 & C. albicans & Poitiers Hospital & 0.094 & 0.008 & 0.047 \\
1156 & C. albicans & Poitiers Hospital & 0.064 & 0.008 & 0.047 \\
1160 & C. albicans & Poitiers Hospital & 0.064 & 0.012 & 0.064 \\
1163 & C. albicans & Poitiers Hospital & 0.094 & 0.012 & 0.032 \\
1 & C. glabrata & Versailles Hospital & 0.19 & 0.008 & 2 \\
767 & C. glabrata & Poitiers Hospital & 0.125 & 0.008 & 2 \\
788 & C. glabrata & Poitiers Hospital & 0.19 & 0.008 & 1.5 \\
924 & C. glabrata & Poitiers Hospital & 0.19 & 0.008 & 2 \\
961 & C. glabrata & Poitiers Hospital & 0.125 & 0.008 & 2 \\
1141 & C. glabrata & Poitiers Hospital & 0.125 & 0.008 & 8 \\
\hline
\end{tabular}

MIC, minimum inhibitory concentration; ATCC, American Type Culture Collection (Manassas, VA). 


\section{Table 2}

Reductions in the metabolic activity of young Candida biofilm yeasts induced by antifungal lock solutions

\begin{tabular}{|c|c|c|c|c|c|c|}
\hline \multirow{3}{*}{$\begin{array}{l}\text { Candida } \\
\text { spp. }\end{array}$} & \multirow{3}{*}{$\begin{array}{l}\text { Post-lock } \\
\text { interval (h) }\end{array}$} & \multicolumn{5}{|c|}{ Decrease in metabolic activity (\%) ${ }^{a}$} \\
\hline & & \multicolumn{2}{|c|}{ Caspofungin } & \multicolumn{2}{|c|}{ Micafungin } & \multirow{2}{*}{$\begin{array}{l}\text { Posaconazole } \\
10 \mathrm{mg} / \mathrm{L}\end{array}$} \\
\hline & & $5 \mathrm{mg} / \mathrm{L}$ & $25 \mathrm{mg} / \mathrm{L}$ & $5 \mathrm{mg} / \mathrm{L}$ & $15 \mathrm{mg} / \mathrm{L}$ & \\
\hline \multirow{6}{*}{$\begin{array}{l}\text { C. } \\
\text { albicans }\end{array}$} & 24 & $81.3 \pm$ & $76.9 \pm$ & $75.1 \pm$ & $70.7 \pm$ & $54.2 \pm 6$ \\
\hline & & 8.8 & 12 & 14.1 & 11.3 & \\
\hline & 48 & $76.8 \pm$ & $78.6 \pm$ & $77.7 \pm$ & $65.4 \pm$ & $49.7 \pm 12$ \\
\hline & & 12.4 & 11.1 & 14.4 & 18.3 & \\
\hline & 72 & $78.6 \pm$ & $79.5 \pm$ & $81.2 \pm$ & $74.8 \pm$ & $41.3 \pm 7.9$ \\
\hline & & 17.4 & 8.3 & 9.3 & 13.3 & \\
\hline \multirow{6}{*}{$\begin{array}{l}\text { C. } \\
\text { glabrata }\end{array}$} & 24 & $76.7 \pm$ & $\mathrm{N} / \mathrm{S}$ & $92.7 \pm$ & $\mathrm{N} / \mathrm{S}$ & None ${ }^{b}$ \\
\hline & & 10.1 & & 0.4 & & \\
\hline & 48 & $55.8 \pm$ & $\mathrm{N} / \mathrm{S}$ & $91.6 \pm$ & $\mathrm{N} / \mathrm{S}$ & None \\
\hline & & 16.7 & & 20.7 & & \\
\hline & 72 & $42.8 \pm$ & N/S & $92.4 \pm$ & $\mathrm{N} / \mathrm{S}$ & None \\
\hline & & 19.1 & & 0.8 & & \\
\hline
\end{tabular}

N/S, not studied.

${ }^{\text {a }}$ Decreases are calculated as the mean reduction for each species (10 strains of $C$. albicans and 6 of $C$. glabrata; Table 1); mean reductions are presented for each antifungal concentration tested $(5 \mathrm{mg} / \mathrm{L}$ and $25 \mathrm{mg} / \mathrm{L}$ caspofungin, $5 \mathrm{mg} / \mathrm{L}$ and 15 $\mathrm{mg} / \mathrm{L}$ micafungin and $10 \mathrm{mg} / \mathrm{L}$ posaconazole) and for each post-lock interval studied (24, 48 or 72 h).

${ }^{\mathrm{b}}$ None indicates that no inhibition was measured. 


\section{Table 3}

Reductions in the metabolic activity of mature Candida biofilm yeasts induced by antifungal lock solutions

\begin{tabular}{|c|c|c|c|c|c|c|}
\hline \multirow{3}{*}{$\begin{array}{l}\text { Candida } \\
\text { spp. }\end{array}$} & \multirow{3}{*}{$\begin{array}{l}\text { Post-lock } \\
\text { interval (h) }\end{array}$} & \multicolumn{5}{|c|}{ Decrease in metabolic activity (\%) ${ }^{a}$} \\
\hline & & \multicolumn{2}{|c|}{ Caspofungin } & \multicolumn{2}{|c|}{ Micafungin } & \multirow{2}{*}{$\begin{array}{l}\text { Posaconazole } \\
10 \mathrm{mg} / \mathrm{L}\end{array}$} \\
\hline & & $5 \mathrm{mg} / \mathrm{L}$ & $25 \mathrm{mg} / \mathrm{L}$ & $5 \mathrm{mg} / \mathrm{L}$ & $15 \mathrm{mg} / \mathrm{L}$ & \\
\hline \multirow{4}{*}{$\begin{array}{l}\text { C. } \\
\text { albicans }\end{array}$} & 24 & $84.1 \pm 7$ & $75.2 \pm$ & $71.7 \pm$ & $66.4 \pm$ & $57.6 \pm 3.5$ \\
\hline & & & 15.3 & 15.3 & 13.3 & \\
\hline & 48 & $80.4 \pm$ & $81.5 \pm$ & $78.7 \pm$ & $75.9 \pm$ & $48.4 \pm 6.8$ \\
\hline & & 11.1 & 8.5 & 16.1 & 18.3 & \\
\hline \multirow{3}{*}{$\begin{array}{l}\text { C. } \\
\text { glabrata }\end{array}$} & 24 & $77.7 \pm$ & $N / S$ & $87.5 \pm$ & NS & None ${ }^{b}$ \\
\hline & & 10.6 & & 11.9 & & \\
\hline & 48 & $\begin{array}{c}44.4 \pm \\
18.5\end{array}$ & $N / S$ & $\begin{array}{c}90.3 \pm \\
4.3\end{array}$ & NS & None \\
\hline
\end{tabular}

N/S, not studied.

${ }^{a}$ Decreases are calculated as the mean reduction for each species (10 strains of $C$. albicans and 6 of $C$. glabrata; Table 1); mean reductions are presented for each antifungal concentration tested $(5 \mathrm{mg} / \mathrm{L}$ and $25 \mathrm{mg} / \mathrm{L}$ caspofungin, $5 \mathrm{mg} / \mathrm{L}$ and 15 $\mathrm{mg} / \mathrm{L}$ micafungin and $10 \mathrm{mg} / \mathrm{L}$ posaconazole) and for each post-lock interval studied (24 h or $48 \mathrm{~h})$.

${ }^{\mathrm{b}}$ None indicates that no inhibition was measured. 